Chapter 7

\title{
Different Performance of Factors Affecting the Estimation of the Corrosion Rate in Magnesium Alloys by Implementation of the Common Methods for Electrochemical Measurements
}

\author{
Alejandro Samaniego and Sebastián Feliu (Jr) \\ Additional information is available at the end of the chapter
}

http://dx.doi.org/10.5772/58370

\section{Introduction}

The attractive properties of magnesium-based alloys make them materials of considerable interest, but their insufficient corrosion resistance is sometimes an impediment to their widespread use. This explains why much current research is focused on better understanding and improving the corrosion behaviour of these alloys.

Such research often relies on the results of immersion tests in aqueous chloride solutions, which have generally proven to be highly appropriate for a quick characterisation and classification of the corrosion resistance of the different magnesium alloys. Corrosion tests in chloridecontaining media may, however, be subject to a serious problem as has been noted by several authors [1-3], in that important discrepancies are sometimes seen between the magnitude of the experimental values and expected values based on available information on the typical behaviour of these alloys. In this respect it is a well known fact that much lower electrochemical corrosion rate values may be obtained with magnesium alloys immersed in some corrosive media than the real values determined gravimetrically. In the literature, this behaviour has tentatively been associated with several phenomena such as material disintegration, the participation of monovalent $\mathrm{Mg}^{+}$ions in the corrosion process, and anomalous chemical dissolution, although the true causes of such discrepancies remains to be fully clarified. 
The purpose of this chapter is to report part of the results of a study carried out on $\mathrm{Mg}-\mathrm{Al}$ alloys which provides new information on the occasional occurrence of anomalous corrosion rates in the study of these alloys. The ultimate aim is to contribute to obtain a best picture of such phenomenon, and to improve from the design of the tests the reliability of the experimental results, removing factors potentially responsible for the anomalous behaviour.

Specifically, this chapter addresses the effect on the electrochemical measurements of the corrosion rate of AZ31 and AZ61 alloys of the: (a) configuration of the exposed surface area of the specimens; (b) surface conditions at the start of the test; and (c) measurement time using the two aforementioned commercial magnesium-aluminium alloys. Special attention has been paid to the possible repercussion of the confinement of the exposed area by means of a circular plastic gasket, as well as to the presence of cut edges on the square coupon specimens entirely exposed to the aggressive solution. Depending on the special circumstances of each case, examination of the corroded surfaces may show substantially varied morphologies, which include uniform corrosion, filiform corrosion, and localized attack with the formation of pits and cavities.

\section{Experimental}

Specimens. The experimental specimens used in the study represent the effect of the following variables: two types of $\mathrm{Mg}$-Al alloys, two surface states, and three different surface areas exposed to the corrosive solution. As will be seen below, all of these variables may have affected the corrosion behavior of the specimens immersed in $0.6 \mathrm{M} \mathrm{NaCl}$ in some way.

The tested alloy types were AZ31 and AZ61, whose nominal compositions (wt.\%) are listed in Table 1. The tests included surfaces in the as-received condition and polished surfaces to a mirror finish. The geometric surfaces areas exposed to the solution were: $0.5 \mathrm{~cm}^{2}, 0.8 \mathrm{~cm}^{2}$ and $9.0 \mathrm{~cm}^{2}$, defined by the circular contour of a plastic polymer gasket.

\begin{tabular}{ccccccccc}
\hline Alloy & $\mathrm{Al}$ & $\mathrm{Zn}$ & $\mathrm{Mn}$ & $\mathrm{Si}$ & $\mathrm{Fe}$ & $\mathrm{Ca}$ & $\mathrm{Mg}$ \\
\hline AZ31 & 3.1 & 0.73 & 0.25 & 0.02 & 0.005 & 0.0014 & Bal. \\
\hline AZ61 & 6.2 & 0.74 & 0.23 & 0.04 & 0.004 & 0.0013 & Bal. \\
\hline
\end{tabular}

Table 1. Composition of alloys

\section{Results and discussion}

\subsection{Corrosion rates}

The graph in Fig.1 plots the normalized corrosion rates (NCR), calculated by dividing the experimentally determined corrosion rate for each specimen by the median value of the set of 
specimens to which the considered specimen belongs (Tables 2-5). As can be seen, there is some variability in the points in relation to the median value indicated by the line NCR=1. The greatest degree of deviation is obviously shown by the outliers located well above the level $\mathrm{NCR}=3$, with values that multiply the median value by as much as 5-20 times.

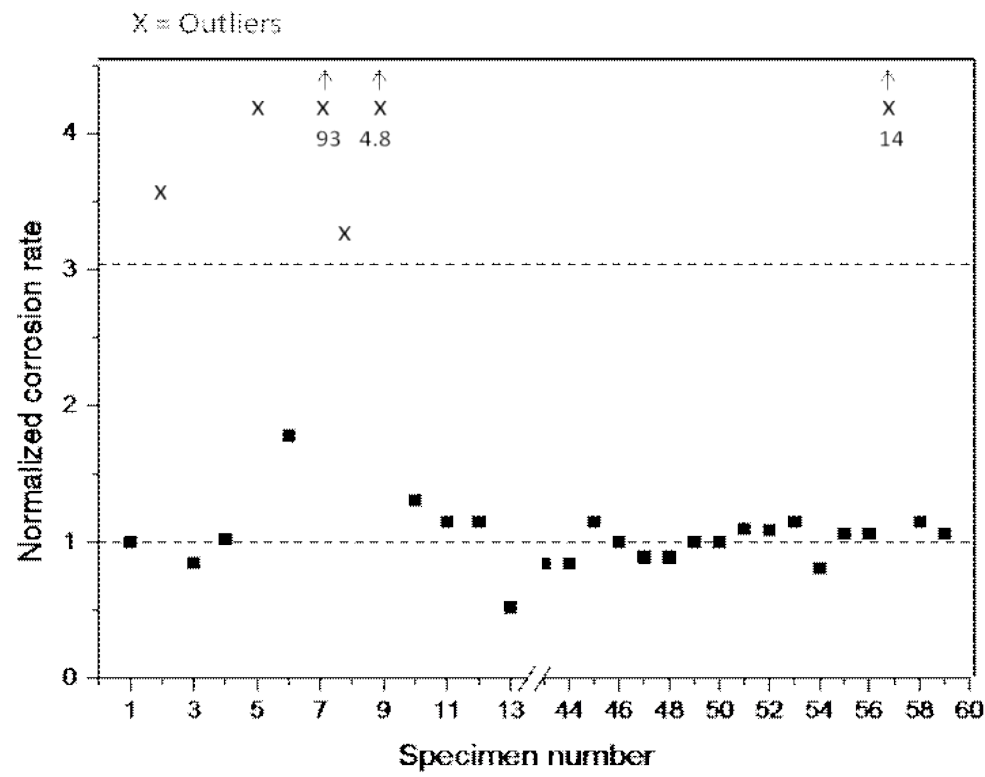

Figure 1. Ratio between gravimetric (GRAV.) and electrochemical (ELEC.) data. The points marked with the letter A correspond to specimens that showed anomalous dissolution rates in weight loss measurements.

\begin{tabular}{cccccc}
\hline $\begin{array}{c}\text { Corrosion rate } \\
\left(\mathbf{m g} / \mathbf{c m}^{2} / \mathrm{d}\right)\end{array}$ & $\begin{array}{c}\text { Normalized } \\
\text { corrosion rate }\end{array}$ & Specimen No. & Days immersion & $\begin{array}{c}\text { Exposed surface } \\
(\mathbf{c m})^{2}\end{array}$ & $\begin{array}{c}\text { Measurement } \\
\text { method }\end{array}$ \\
\hline 0.26 & 0.41 & 18 & 10 & 10.5 & W \\
\hline 0.31 & 0.48 & 17 & 10 & 10.5 & $\mathrm{~W}$ \\
\hline 0.38 & 0.59 & 70 & 10 & 10.4 & $\mathrm{H}$ \\
\hline
\end{tabular}




\begin{tabular}{|c|c|c|c|c|c|}
\hline $\begin{array}{c}\text { Corrosion rate } \\
\left(\mathrm{mg} / \mathrm{cm}^{2} / \mathrm{d}\right)\end{array}$ & $\begin{array}{l}\text { Normalized } \\
\text { corrosion rate }\end{array}$ & Specimen No. & Days immersion & $\begin{array}{l}\text { Exposed surface } \\
(\mathrm{cm})^{2}\end{array}$ & $\begin{array}{c}\text { Measurement } \\
\text { method }\end{array}$ \\
\hline 0.38 & 0.59 & 69 & 10 & 10.4 & $\mathrm{H}$ \\
\hline 0.49 & 0.77 & 62 & 7 & 10.4 & $\mathrm{H}$ \\
\hline 0.50 & 0.78 & 88 & 4 & 10.4 & $\mathrm{H}$ \\
\hline 0.50 & 0.78 & 87 & 4 & 10.4 & $\mathrm{H}$ \\
\hline 0.51 & 0.80 & 61 & 7 & 10.4 & $\mathrm{H}$ \\
\hline 0.54 & 0.84 & 43 & 4 & 10.4 & $\mathrm{H}$ \\
\hline 0.54 & 0.84 & 44 & 4 & 10.4 & H \\
\hline 0.57 & 0.89 & 47 & 4 & 10.4 & $\mathrm{H}$ \\
\hline 0.57 & 0.89 & 48 & 4 & 10.4 & $\mathrm{H}$ \\
\hline 0.63 & 0.98 & 78 & 4 & 0.8 & $\mathrm{H}$ \\
\hline 0.64 & 1.00 & 1 & 10 & 0.4 & W \\
\hline 0.68 & 1.06 & 55 & 4 & 10.4 & $\mathrm{H}$ \\
\hline 0.68 & 1.06 & 56 & 4 & 10.4 & $\mathrm{H}$ \\
\hline 0.84 & 1.31 & 10 & 3 & 9 & W \\
\hline 0.93 & 1.45 & 86 & 4 & 6 & $\mathrm{H}$ \\
\hline 1.16 & 1.81 & 36 & 1 & 10.4 & $\mathrm{H}$ \\
\hline 1.21 & 1.89 & 35 & 1 & 10.4 & H \\
\hline 1.70 & 2.66 & 85 & 4 & 6 & $\mathrm{H}$ \\
\hline 2.30 & 3.59 & 2 & 10 & 0.4 & W \\
\hline 2.71 & 4.23 & 77 & 4 & 0.8 & $\mathrm{H}$ \\
\hline 3.05 & 4.77 & 9 & 3 & 9 & W \\
\hline 7.55 & 11.8 & 72 & 6 & 0 & $\mathrm{H}$ \\
\hline 9.22 & 14.4 & 57 & 4 & 0 & $\mathrm{H}$ \\
\hline 15.7 & 24.5 & 71 & 3 & 0 & $\mathrm{H}$ \\
\hline
\end{tabular}

Table 2. Average corrosion rates arranged in ascending order. Specimens of AZ31 alloy in the as-received surface condition (Measurements: W, by weight loss; H, by hydrogen evolution). 


\begin{tabular}{|c|c|c|c|c|c|}
\hline $\begin{array}{l}\text { Corrosion rate } \\
\left(\mathrm{mg} / \mathrm{dm}^{2} / \mathrm{d}\right)\end{array}$ & $\begin{array}{c}\text { Normalized } \\
\text { corrosion rate }\end{array}$ & $\begin{array}{c}\text { Specimen } \\
\text { No }\end{array}$ & Days immersion & $\begin{array}{l}\text { Exposed surface } \\
\qquad\left(\mathrm{cm}^{2}\right)\end{array}$ & $\begin{array}{c}\text { Measurement } \\
\text { method }\end{array}$ \\
\hline 0.20 & 0.32 & 19 & 10 & 10.5 & W \\
\hline 0.21 & 0.34 & 20 & 10 & 10.5 & W \\
\hline 0.53 & 0.85 & 3 & 10 & 0.4 & w \\
\hline 0.53 & 0.85 & 64 & 7 & 10.4 & $\mathrm{H}$ \\
\hline 0.54 & 0.87 & 63 & 7 & 10.4 & H \\
\hline 0.55 & 0.89 & 91 & 4 & 10.4 & $\mathrm{H}$ \\
\hline 0.55 & 0.89 & 92 & 4 & 10.4 & $\mathrm{H}$ \\
\hline 0.56 & 0.90 & 90 & 4 & 6 & $\mathrm{H}$ \\
\hline 0.62 & 1.00 & 49 & 4 & 10.4 & $\mathrm{H}$ \\
\hline 0.62 & 1.00 & 50 & 4 & 10.4 & $\mathrm{H}$ \\
\hline 0.63 & 1.02 & 4 & 10 & 0.4 & W \\
\hline 0.63 & 1.02 & 89 & 4 & 6 & $\mathrm{H}$ \\
\hline 0.68 & 1.10 & 80 & 4 & 0.8 & $\mathrm{H}$ \\
\hline 0.71 & 1.15 & 11 & 3 & 9 & W \\
\hline 0.71 & 1.15 & 12 & 3 & 9 & W \\
\hline 1.31 & 2.11 & 37 & 1 & 10.4 & $\mathrm{H}$ \\
\hline 1.40 & 2.26 & 38 & 1 & 10.4 & $\mathrm{H}$ \\
\hline 10.90 & 17.6 & 79 & 4 & 0.8 & $\mathrm{H}$ \\
\hline
\end{tabular}

Table 3. Average corrosion rates arranged in ascending order. Specimens of the AZ31 alloy in the as-polished surface condition. (measurements: W, by weight loss; $\mathrm{H}$, by hydrogen evolution).

\begin{tabular}{cccccc}
\hline $\begin{array}{c}\text { Corrosion rate } \\
\left(\mathbf{m g} / \mathbf{c m}^{2} \mathbf{d}\right)\end{array}$ & $\begin{array}{c}\text { Normalized } \\
\text { corrosion rate }\end{array}$ & Specimen No & Days immersion & $\begin{array}{c}\text { Exposed surface } \\
\left(\mathbf{c m}^{2}\right)\end{array}$ & $\begin{array}{c}\text { Measurement } \\
\text { method }\end{array}$ \\
\hline 0.54 & 0.18 & 82 & 4 & 0.8 & $\mathrm{H}$ \\
\hline 0.88 & 0.29 & 14 & 3 & 9 & $\mathrm{~W}$ \\
\hline 1.03 & 0.33 & 21 & 10 & 10.5 & $\mathrm{~W}$ \\
\hline 1.28 & 0.42 & 94 & 4 & 6 & $\mathrm{H}$ \\
\hline
\end{tabular}




\begin{tabular}{|c|c|c|c|c|c|}
\hline $\begin{array}{l}\text { Corrosion rate } \\
\left(\mathrm{mg} / \mathrm{cm}^{2} / \mathrm{d}\right)\end{array}$ & $\begin{array}{c}\text { Normalized } \\
\text { corrosion rate }\end{array}$ & Specimen No & Days immersion & $\begin{array}{c}\text { Exposed surface } \\
\qquad\left(\mathrm{cm}^{2}\right)\end{array}$ & $\begin{array}{c}\text { Measurement } \\
\text { method }\end{array}$ \\
\hline 1.30 & 0.42 & 26 & 3 & 10.4 & W \\
\hline 1.35 & 0.44 & 22 & 10 & 10.5 & W \\
\hline 1.49 & 0.48 & 60 & 4 & 0.84 & $\mathrm{H}$ \\
\hline 1.51 & 0.49 & 76 & 6 & 0.8 & $\mathrm{H}$ \\
\hline 1.61 & 0.52 & 13 & 3 & 9 & W \\
\hline 1.80 & 0.58 & 25 & 3 & 10.4 & W \\
\hline 2.13 & 0.69 & 29 & 3 & 10.4 & W \\
\hline 2.75 & 0.89 & 96 & 4 & 10.4 & $\mathrm{H}$ \\
\hline 2.82 & 0.92 & 73 & 10 & 10.4 & $\mathrm{H}$ \\
\hline 2.82 & 0.92 & 74 & 10 & 10.4 & $\mathrm{H}$ \\
\hline 2.90 & 0.94 & 30 & 3 & 10.4 & W \\
\hline 3.08 & 1.00 & 95 & 4 & 10.4 & $\mathrm{H}$ \\
\hline 3.09 & 1.00 & 46 & 4 & 10.4 & $\mathrm{H}$ \\
\hline 3.21 & 1.04 & 39 & 1 & 10.4 & $\mathrm{H}$ \\
\hline 3.26 & 1.06 & 59 & 4 & 10.4 & $\mathrm{H}$ \\
\hline 3.36 & 1.09 & 52 & 4 & 10.4 & $\mathrm{H}$ \\
\hline 3.39 & 1.10 & 51 & 4 & 10.4 & $\mathrm{H}$ \\
\hline 3.44 & 1.12 & 66 & 7 & 10.4 & $\mathrm{H}$ \\
\hline 3.53 & 1.15 & 45 & 4 & 10.4 & $\mathrm{H}$ \\
\hline 3.53 & 1.15 & 58 & 4 & 0.84 & $\mathrm{H}$ \\
\hline 3.66 & 1.19 & 81 & 4 & 0.8 & $\mathrm{H}$ \\
\hline 3.68 & 1.19 & 65 & 7 & 10.4 & $\mathrm{H}$ \\
\hline 4.00 & 1.30 & 31 & 3 & 10.4 & W \\
\hline 5.48 & 1.78 & 6 & 10 & 0.4 & W \\
\hline 5.50 & 1.79 & 93 & 4 & 6 & $\mathrm{H}$ \\
\hline 11.8 & 3.83 & 75 & 3 & 0.8 & $\mathrm{H}$ \\
\hline 12.8 & 4.16 & 5 & 10 & 0.4 & W \\
\hline
\end{tabular}

Table 4. Average corrosion rates arranged in ascending order. Specimens of the AZ61 alloy in the as-received surface condition. (measurements: W. by weight loss; $\mathrm{H}$, by hydrogen evolution) 


\begin{tabular}{|c|c|c|c|c|c|}
\hline $\begin{array}{l}\text { Corrosion rate } \\
\left(\mathrm{mg} / \mathrm{cm}^{2} / \mathrm{d}\right)\end{array}$ & $\begin{array}{l}\text { Normalized } \\
\text { corrosion rate }\end{array}$ & Specimen No & Days immersion & $\begin{array}{l}\text { Exposed surface } \\
\qquad\left(\mathrm{cm}^{2}\right)\end{array}$ & $\begin{array}{c}\text { Measurement } \\
\text { method }\end{array}$ \\
\hline 0.27 & 0.50 & 28 & 3 & 10.4 & W \\
\hline 0.28 & 0.52 & 15 & 3 & 9 & W \\
\hline 0.33 & 0.61 & 27 & 3 & 10.4 & W \\
\hline 0.33 & 0.61 & 84 & 4 & 0.8 & $\mathrm{H}$ \\
\hline 0.38 & 0.70 & 100 & 4 & 10.4 & $\mathrm{H}$ \\
\hline 0.38 & 0.70 & 98 & 4 & 6 & $\mathrm{H}$ \\
\hline 0.38 & 0.70 & 16 & 3 & 9 & W \\
\hline 0.43 & 0.80 & 33 & 3 & 10.4 & $\mathrm{H}$ \\
\hline 0.43 & 0.80 & 54 & 4 & 10.4 & $\mathrm{H}$ \\
\hline 0.47 & 0.87 & 41 & 1 & 10.4 & $\mathrm{H}$ \\
\hline 0.53 & 0.98 & 67 & 7 & 10.4 & $\mathrm{H}$ \\
\hline 0.53 & 0.98 & 99 & 4 & 10.4 & $\mathrm{H}$ \\
\hline 0.55 & 1.08 & 97 & 4 & 6 & $\mathrm{H}$ \\
\hline 0.56 & 1.04 & 24 & 10 & 10.5 & W \\
\hline 0.58 & 1.07 & 23 & 10 & 10.5 & W \\
\hline 0.58 & 1.07 & 42 & 1 & 10.4 & $\mathrm{H}$ \\
\hline 0.61 & 1.13 & 43 & 4 & 10.4 & $\mathrm{H}$ \\
\hline 0.70 & 1.30 & 34 & 3 & 10.4 & W \\
\hline 0.81 & 1.50 & 68 & 7 & 10.4 & $\mathrm{H}$ \\
\hline 0.84 & 1.56 & 32 & 3 & 10.4 & W \\
\hline 1.25 & 2.31 & 83 & 4 & 0.8 & $\mathrm{H}$ \\
\hline 1.73 & 3.20 & 8 & 10 & 0.4 & W \\
\hline 3.10 & 5.74 & 40 & 1 & 10.4 & $\mathrm{H}$ \\
\hline 49.3 & 91.3 & 7 & 10 & 0.4 & W \\
\hline
\end{tabular}

Table 5. Average corrosion rates arranged in ascending order. Specimens of the AZ61 alloy in the as-polished surface condition (measurements: W, by weight loss; H, by hydrogen evolution). 


\subsection{Variability in the results}

The relatively moderate differences in the corrosion rate (factors of about 1.5-2) found in repeated tests are not surprising bearing in mind the random nature of the attack, as well as the possible uncontrolled small changes in the experimental conditions of tests. In general, the attack tends to be concentrated in areas where the protective action of the oxide film on the metallic surface is lowest due to lacks of continuity or lower stability. It is logical for the corrosion process to depend on the distribution and importance of defect sites in the oxide film and the distribution of passive/active states at points on the exposed surface. Observation of the corroded surfaces has revealed a lack of homogeneity in the attack, in which areas of uniform attack can coincide with areas of heterogeneous corrosion, isolated pitting and/or clusters of filiform corrosion [4].

\subsection{Anomalous behavior}

Apart from the above-mentioned variability of the results, which can be considered as "normal", the aspect that particularly draws attention is the high corrosion rate values-far removed from the mass of data-that sporadically and unpredictably appears in the corrosion tests. For the purposes of the present work, the term "anomalous" will be applied whenever the corrosion rates exceed at least triple the normal results defined by the median values, taking normality in the statistical sense.

\subsection{Effect of surface state and alloy type}

Through this analysis of the possible influence of diverse factors on the variability of the corrosion results, one of the factors considered has been the surface state of the tested specimens

In this work, corrosion rates for the AZ31 and AZ61 magnesium alloys immersed in the $0.6 \mathrm{M}$ $\mathrm{NaCl}$ showed values mostly between $0.5-1 \mathrm{mg} / \mathrm{cm}^{2} / \mathrm{d}$ for AZ31 alloy and $0.5-3 \mathrm{mg} / \mathrm{cm}^{2} / \mathrm{d}$ for AZ61. These corrosion rates are summarized in Tables 2-5, where the data are set out in increasing order. The median values (middle value in the list of numbers) for the AZ31 alloy specimens is $0.64 \mathrm{mg} / \mathrm{cm}^{2} / \mathrm{d}$ in the as-received condition and $0.62 \mathrm{mg} / \mathrm{cm}^{2} / \mathrm{d}$ in polished surface condition. Much more noticeable is the effect of surface state for the AZ61 specimens, with median values of $3.08 \mathrm{mg} / \mathrm{cm}^{2} / \mathrm{d}$ for the as-received condition and $0.54 \mathrm{mg} / \mathrm{cm}^{2} / \mathrm{d}$ for the polished condition. The higher corrosion rate in the as-received condition for the AZ61 alloy suggests a combined effect of an oxide film of lower quality and an enhanced micro-galvanic action due to the abundant presence of $\beta$-phase in this alloy.

From the analysis of Tables 2-5 and Table 6 it can be deduced also that the AZ31 alloy specimens present a greater tendency towards anomalous behavior ( 7 cases in 45 tested specimens) than the AZ61 specimens ( 3 cases in 57 tested specimens), and that the frequency of cases of anomalous behavior does not depend exclusively on the alloy type, as it is notably lower for the AZ31 alloy in polished surface condition than in the as-received condition. 


\begin{tabular}{lc}
\hline Alloy type: & \\
\hline AZ31 & 7 cases per 45 tested specimens \\
\hline AZ61 & 3 cases per 57 tested specimens \\
\hline Surface condition: & 8 cases per 59 tested specimens \\
\hline As-received surface & 2 cases per 42 tested specimens \\
\hline As-polished surface & 3 cases per 8 tested specimens \\
\hline Exposed surface area defined by the contour of a circular gasket \\
\hline $0.5 \mathrm{~cm}^{2}$ & 6 cases per 14 tested specimens \\
\hline $0.8 \mathrm{~cm}^{2}$ & 1 case per 8 tested specimens \\
\hline $9.0 \mathrm{~cm}^{2}$ & 5 cases per 64 tested specimens \\
\hline Specimen of $2 \mathrm{~cm} \times 2 \mathrm{~cm} \times 0.3 \mathrm{~cm}$ suspended vertically & \\
\hline
\end{tabular}

Table 6. Frequency of cases of anomalous behavior for different exposure conditions and composition of the specimens.

\subsection{Effect of exposed surface area}

The effect of the geometric surface area was studied with specimens of the alloys AZ31 and AZ61 exposing a free surface areas of $0.5 \mathrm{~cm}^{2}, 0.8 \mathrm{~cm}^{2}$ and $9.0 \mathrm{~cm}^{2}$, delimited by the contour of circular plastic gaskets on the specimens in horizontal position. The results obtained, summarized in Table 6, shows a propensity to abnormal behaviour when the exposed area of the flat specimens is $\leq 0.8 \mathrm{~cm}^{2}$. In this regard, Fig. 2 is an example of different morphologies of attack associated with the exposed surface area, being notably the presence of large irregular pits in the case of the small surface area exposed.
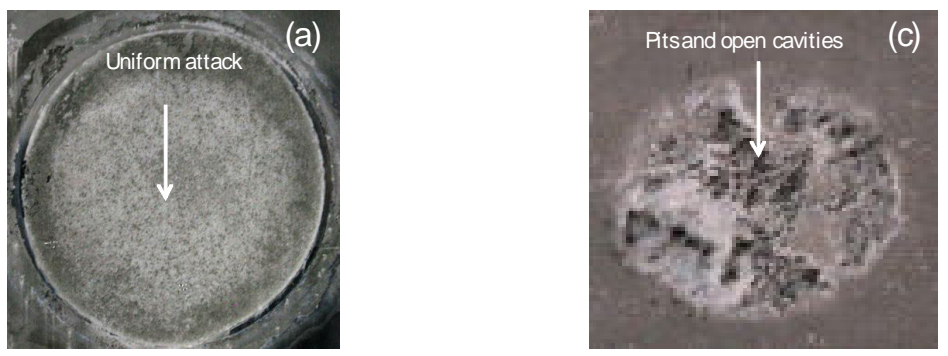

Figure 2. Surface appearance after immersion in $0.6 \mathrm{M} \mathrm{NaCl}$ solution for 14 days at $24{ }^{\circ} \mathrm{C}$ and after removal of corrosion products. AZ31 specimen with the original surface in the as-received condition, Exposed circular area of $\sim 9 \mathrm{~cm}^{2} X$ 0.75 approxExposed circular area of $\sim 0.4 \mathrm{~cm}^{2} \times 0.75$ approx 
Shi and Atrens [5] have reported that the corrosion rate of magnesium can be affected by the presence of crevices between the metallic specimen and the epoxy resin mounting in which is embedded, which can cause increases of the order of $50-100 \%$ in the corrosion rate. This suggests a possible crevice effect between the plastic gasket and the metallic surface. However, there are two reasons to doubt whether the anomalous behavior mentioned in this work can be explained by such a phenomenon: (i) the much greater magnitude of the corrosion rate that defines anomalous behaviour and (ii) the fact that notable attack of the metal is not observed under the plastic gasket.

Table 6 also suggests an almost insignificant tendency towards anomalous behaviour in the case of the specimens immersed in vertical position with their entire surface $\left(\sim 10.4 \mathrm{~cm}^{2}\right)$ exposed to the saline medium. One practical conclusion that may be drawn from Table 6 is that an area of around $10 \mathrm{~cm}^{2}$ or greater reduces the risk of the appearance of anomalous results.

It is logical to relate an increase in the corrosion rate with the weakening, breaking up or disappearance of the oxide film that usually protects the surface of magnesium alloys. Any increase in the percentage of active points or oxide-free areas on the metallic surface will favour the tendency (stimulated by the presence of $\mathrm{Cl}$-ions) for metallic ions to pass from the reactive bare surface into the aqueous solution. Anomalous behaviour will probably be triggered in special circumstances when a large highly reactive area appears on the surface. Restoration of the passive oxide film would obviously inhibit anomalous corrosion, and so accelerated dissolution will only proceed if the surface is permanently activated by a process that reduces the thin oxide film which spontaneously tends to form on the metallic surface in contact with air.

A specific cause in the present work that has been favourable to the appearance of anomalous corrosion is the presence of a gasket that delimits a small exposed area upon which a persistent crowded population of hydrogen bubbles is likely to develop and maintain during the corrosion process, This suggests a possible association between circumstances related with the evolution of hydrogen and the activation of isolated regions on the metallic surface, which cease to be controlled by the oxide film mechanism. This film may be ruptured by the combined action of $\mathrm{Cl}$-ions and the extremely reactive nascent hydrogen, with the formation of a reducing atmosphere in which metal oxidation and restoration of the passive film is not possible. It may be speculated that factors related with the formation, permanence and disturbance of the hydrogen bubble layer exert some influence on the incubation of the above phenomenon.

The greater tendency for specimens with a small exposed area delimited by a circular gasket to behave anomalously in this work suggests the influence of this configuration on the special properties of the evolved hydrogen bubbles. Supposing a role of bubble removal, an effect of specimen geometry and hydrodynamics of the liquid environment may be expected.

The greater adhesion of bubbles on a rough surface is translated into a prolongation of the bubble residence time [6]. Perhaps connected with this fact is the more likely occurrence (Table 7) of anomalous behavior on the significantly rougher as-received surfaces. 


\begin{tabular}{|c|c|c|c|c|}
\hline \multicolumn{3}{|c|}{ Specimen } & \multicolumn{2}{|c|}{ Corrosion rate data $\left(\mathrm{mg} / \mathrm{cm}^{2} / \mathrm{d}\right)$} \\
\hline No & Alloy & Surface $\left({ }^{*}\right)$ condition & electrochemical & Gravimetric \\
\hline 1 & AZ31 & $\mathrm{O}$ & 0.20 & 0.51 \\
\hline 2 & AZ31 & $\mathrm{O}$ & 0.25 & 1.84 \\
\hline 3 & AZ31 & $P$ & 0.38 & 0.42 \\
\hline 4 & AZ31 & $P$ & 0.40 & 0.50 \\
\hline 5 & AZ61 & $\mathrm{O}$ & 1.60 & 10.25 \\
\hline 6 & AZ61 & $\mathrm{O}$ & 2.85 & 4.38 \\
\hline 7 & AZ61 & $P$ & 1.68 & 39.4 \\
\hline 8 & AZ61 & $P$ & 1.64 & 1.38 \\
\hline 9 & AZ31 & $\mathrm{O}$ & 2.81 & 3.05 \\
\hline 10 & AZ31 & $\mathrm{O}$ & 0.81 & 0.84 \\
\hline 11 & AZ31 & $P$ & 0.71 & 0.71 \\
\hline 12 & AZ31 & $P$ & 0.75 & 0.71 \\
\hline 13 & AZ61 & $\mathrm{O}$ & 1.71 & 1.61 \\
\hline 14 & AZ61 & $\mathrm{O}$ & 0.84 & 0.88 \\
\hline 15 & AZ61 & $P$ & 0.36 & 0.28 \\
\hline 16 & AZ61 & $P$ & 0.30 & 0.38 \\
\hline
\end{tabular}

(*) O=as-received; P=as-polished

Table 7. Comparison of corrosion losses estimated from electrochemical and gravimetric measurements for AZ31 and AZ61 alloys.

\subsection{Underestimated electrochemical data}

Different studies have shown that serious discrepancies may occur between electrochemical and gravimetric determinations of the corrosion rate of magnesium alloys, resulting in much lower electrochemical values than the real values determined gravimetrically $[3,7,9]$. In the literature, this behaviour has tentatively been associated with several phenomena, such as material disintegration, the participation of monovalent $\mathrm{Mg}^{+}$ions in the corrosion process, and anomalous chemical dissolution, although the true cause of the large discrepancies remains to be fully clarified [10-14].

Logically the above leads to uncertainty with regard to the application of electrochemical methods to estimate the corrosion rate of magnesium alloys, especially in media containing chloride ions.

Using a series of 16 specimens (Nos. 1-16 in Table 7), electrochemical and gravimetric corrosion rate data has been simultaneously obtained with them to allow comparison between the two types of measurements. Fig.3 constructed with this data shows satisfactory consistency between both types of corrosion rate determinations for 12 of the 16 tested specimens, but not for the other four (specimens 1, 2, 5 and 7), where notable differences were seen; with electro- 
chemical estimations of up to 20 times lower than the real corrosion rates determined by gravimetric measurements.

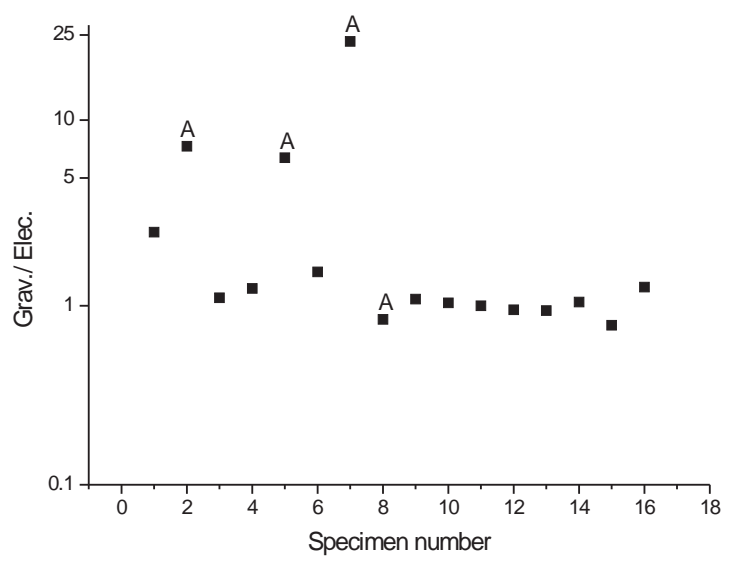

Figure 3. Ratio between gravimetric (GRAV.) and electrochemical (ELEC.) data. The points marked with the letter A correspond to specimens that showed anomalous dissolution rates in weight loss measurements.

An explanation for these cases of strong discrepancy is to accept that only a fraction of the metallic surface really contributes to the electrochemical response; for instance when the material simultaneously disintegrates into fine metallic particles during the corrosive attack [10-12] or when part of the corrosion process is chemical rather than electrochemical, so the simultaneous independent chemical dissolution processes cannot be monitored by electrochemical means $[8,9]$.

In the case of abundant hydrogen evolution, as in the attack of magnesium alloys in $0.6 \mathrm{M}$ $\mathrm{NaCl}$, the possibility has also been mentioned that gas bubbles adhering to the metal surface and insulating a fraction of it from the electrical signal applied during electrochemical measurements substantially affect the system's response, as electrochemical data does not account for the entire corrosion process on the exposed surface $[5,15]$.

It is interesting to note that in three of the four specimens on which great differences have been seen between gravimetric and electrochemical weigh loss determinations (specimens 2, 5 and 7 in Fig.3), this behaviour has coincided with the occurrence of anomalous corrosion rates. The coincidence of both phenomena suggests that the electrochemical corrosion process only partly controls metallic dissolution in the case of anomalous behaviour, and that along with the normal corrosion reaction another non-electrochemical mechanism must play an essential role in the accelerated corrosion process. 


\subsection{Effect of pre-existing film and time of exposure to the test solution}

This last section is concerned with the possible effect on the corrosion rate measurements, of (i) the native oxide films (just a few nanometers thick) which is spontaneously formed in the air and that may have some protective effect (barrier effect) against corrosion, and (ii) duration of exposure of the specimen under study to the test solution.

The effect of said oxide film seems to depend on the surface condition of metal. It has been found that this effect is more pronounced with the polished surfaces, chiefly of alloy AZ61. In the immersion tests in the $0.6 \mathrm{M} \mathrm{NaCl}$ solution a certain effect of the initial surface condition is revealed in the early stages of the test, principally with the polished specimens of the AZ61 alloy; in it polishing increased the corrosion resistance by a factor of about five whereas in the alloy AZ31 was only duplicated [16].

It is important to mention that, after an initial period which does not last for more than about 7 days, no effect attributable to the initial surface condition is generally seen. With the AZ61 alloy this effect has almost disappeared after 7 days. With the AZ31 alloy the effect of the airformed film is smaller and is lost more slowly [16]. This different effect of surface condition are probably due to the fact that the oxide film formed on the polished surfaces is more uniform, homogeneous and continuous than that on the as-received surfaces resulting from the fabrication of the wrought alloy, on which the film will be discontinuous and porous and not uniformly distributed. From XPS determinations, it was found that the oxide film formed on de polished AZ61 alloy was some $2 \mathrm{~nm}$ thicker than on the as-received condition [16].

\subsubsection{Effect of time of exposure}

In order to facilitate the correct comparisons of corrodibility between specimens, it is desirable to take into account the effect of time of exposure to the corrosive solution; the assumption that corrosion occurs at a constant rate through all the test period may not in fact be true, since there are frequent cases in which corrosion rate tends to decrease or increase over time.

Often, rates of attack tend to diminish as a result of the formation of adhered insoluble corrosion products or protective films originated in the contact with environment. Several studies [17-20] report the formation of layers of corrosion products on the surface of the magnesium alloys immersed in corrosive solutions, which exert some influence on the kinetics of the corrosion process. For this reason, extrapolations of results of too short tests are more likely to indicate lesser resistance to corrosion than will actually be observed over a more prolonged period of exposure. The opposite case may also occur, for example as a result of the deterioration of protective oxide films on the specimen's surface.

Fig.4, constructed with data from a previous investigation by Samaniego et al [4] may serve, as an example, to illustrate some of the features that can lead to erroneous ideas on the real values of corrosion resistance of the AZ31 and AZ61 magnesium alloys, Notable aspects include the marked reduction experienced by the instantaneous corrosion rate with immersion time for the AZ31 specimens and the tendency towards a slight decrease shown by the asreceived surfaces of the AZ61 specimens after about four days immersion, effect explained by 
the presence of a slightly protective air-formed film on the as-received surface in conjunction with an accelerated micro-galvanic corrosion process.

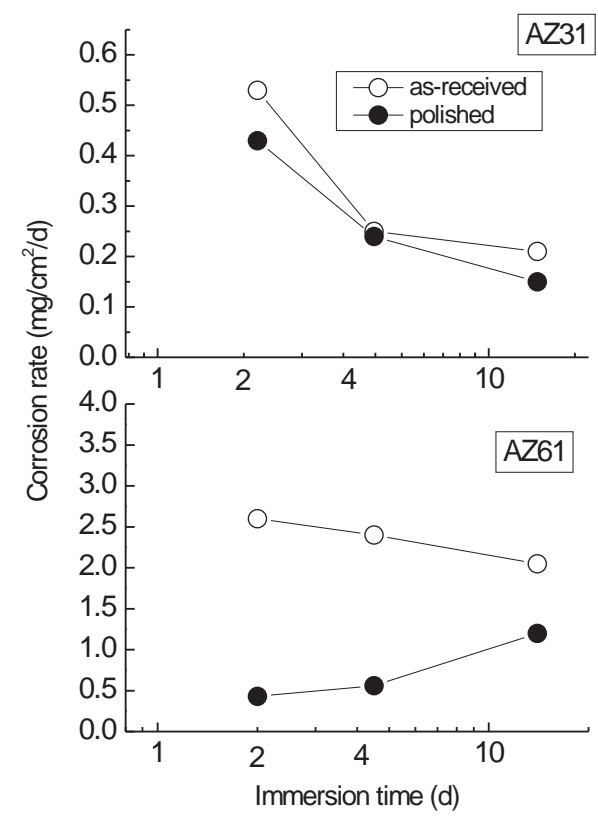

Figure 4. Instantaneous corrosion rate as a function of immersion time in $0.6 \mathrm{M} \mathrm{NaCl}$ solution. Specimens exposing $10.4 \mathrm{~cm}^{2}$.

\section{Conclusions}

1. In the immersion testing of alloys $\mathrm{AZ31}$ and $\mathrm{AZ61}$ in $0.6 \mathrm{M} \mathrm{NaCl}$ solution, anomalous results have occasionally been found in which the corrosion rate greatly surpasses normal values for the tested specimens.

2. A statistical type connection is seen between the frequency of the appearance of this anomalous result and certain characteristics of the tested specimens, in particular, the configuration and area exposed to the corrosive medium.

3. The results suggest some kind of link between anomalous behaviour and the action of hydrogen bubbles adhered to the specimen surface during the corrosion process. 
4. The anomalous behaviour of the specimens tends to coincide with much smaller electrochemical corrosion rate determinations than those obtained by weight loss or hydrogen evolution measurements. This fact suggests that in the anomalous corrosion process only a fraction of the metallic surface really contributes to the electrochemical response.

5. On the basis of the information discussed, the conclusion is drawn that corrosion measurements may give rise to misleading comparisons of corrodibility without specifying the time during which the specimens to be compared are immersed in the corrosive solution.

\section{Acknowledgements}

We wish to express our gratitude to Prof. S. Feliu for several clarifying and stimulating discussions during the course of this work. Also, the authors gratefully acknowledge the financial support for this work from the Ministry of Science and Innovation of Spain (MAT 2009-13530)

\section{Author details}

Alejandro Samaniego and Sebastián Feliu (Jr)

*Address all correspondence to: sfeliu@cenim.csic.es

Centro Nacional de Investigaciones Metalúrgicas CSIC, Madrid, Spain

\section{References}

[1] Song GL, Atrens A. Understanding Magnesium Corrosion-A Framework for Improved Alloy Performance. Advanced Engineering Materials 2003;5(12) 837-858.

[2] Kirkland NT, Birbilis N, Staiger MP. Assessing the Corrosion of Biodegradable Magnesium Implants: A Critical Review of Current Methodologies and their Limitations 2012; Acta Biomaterialia 2012;8(3) 925-936.

[3] Shi ZM, Lin M, Atrens A. Measurement of the Corrosion Rate of Magnesium Alloys Using Tafel Extrapolation. Corrosion Science 2010;52(2) 579-588.

[4] Samaniego A, Llorente I, Feliu Jr. S. Combined Effect of Composition and Surface Condition on Corrosion Behavior of Magnesium Alloys AZ31 and AZ61. Corrosion Science 2013;68 66-71.

[5] Shi ZM, Atrens A. An Innovative Specimen Configuration for the Study of Mg Corrosion. Corrosion Science 2011; 53(1) 226-246. 
[6] Lumanauw D. Hydrogen Bubble Characterization in Alkaline Water Electrolysis. Mster Thesis. University of Toronto; 2000.

[7] Pardo A, Feliu Jr. S, Merino MC, Arrabal R, Matykina E. Electrochemical Estimation of the Corrosion Rate of Magnesium/Aluminium Alloys. International Journal of Corrosion 2010, http://www.hindawi.com/journals/ijc/2010/953850/.

[8] Drazic DM, Popic JP. Anomalous Dissolution of Metals and Chemical Corrosion. Journal of the Serbian Chemical Society 2005; 70(3) 489-511.

[9] Kolotyrkin YM, Florianovich GM. Anomalous Metal Dissolution: Experimental Facts and Theoretical Interpretation. Zashchita Metallov 1984; 20(1) 14-24.

[10] Makar GL, Kruger J. Corrosion Studies of Rapidly Solidified Magnesium Alloys. Journal of the Electrochemical Society 1990; 137(2) 414-421.

[11] Straumanis ME, Bhatia BK. Disintegration of Magnesium while Dissolving Anodically in Neutral and Acidic Solutions. Journal of the Electrochemical Society 1963; 110(5) 357-360.

[12] James WJ, Straumanis ME, Bhatia BK, Jhonson JW. The Difference Effect on Magnesium Dissolving in Acids. Journal of the Electrochemical Society 1963; 110(11) 1117-1120.

[13] Hoey GR, Cohen M. Corrosion of Anodically and Cathodically Polarized Magnesium in Aqueous Media. Journal of the Electrochemical Society 1958; 105(5) 245-250.

[14] Song GL, Atrens A. Corrosion Mechanisms of Magnesium Alloys. Advanced Engineering Materials 1999; 1(1) 11-33.

[15] Vogt H. The Incremental Ohmic Resistance Caused by Bubbles Adhering to an Electrode. Journal of Applied Electrochemistry 1983; 13(1) 87-88.

[16] Feliu Jr. S, Maffiotte C, Samaniego A, Galván JC, Barranco V. Effect of Naturally Formed Oxide Films and other Variables in the Early Stages of Mg-alloy Corrosion in $\mathrm{NaCl}$ Solution. Electrochimica Acta 2011; 56(12) 4554-4565.

[17] Baril G, Pebere N. The Corrosion of Pure Magnesium in Aerated and Deaerated Sodium sulphate solutions. Corrosion Science 2001; 43(3) 471-484.

[18] Pardo A, Merino MC, Coy AE, Viejo F, Arrabal R, Feliu Jr. S. Influence of Microstructure and Composition on the Corrosion Behavior of $\mathrm{Mg} / \mathrm{Al}$ Alloys in Chloride Media. Electrochimica Acta 2008; 53 (27) 7890-7902.

[19] Santamaría M, Di Quarto F, Zanna S, Marcus P. Initial Surface Film on Magnesium Metal: A Characterization by X-ray Photoelectron Spectroscopy (XPS) and Photocurrent Spectroscopy (PCS). Electrochimica Acta 2007; 53(3) 1314-1324. 
[20] Pebere N, Riera C, Dabosi F. Investigation of magnesium corrosion in aerated sodium-sulfate solution by electrochemical impedance spectroscopy. Electrochimica Acta 1990; 35(2) 555-561. 
